\title{
Economic Impact of Climate Change on Maize Productivity: Cross Sectional Data
}

\author{
GETINET GEZAHEGN GEBRE \\ Lecturer, Department of Economics, Bonga University, Ethiopia
}

\begin{abstract}
This study investigates the economic impact of climate change on Maize production in Decha woreda of south west Kafa zone, located at $23 \mathrm{Km}$ from Bonga Town, and $473 \mathrm{~km}$ south west of Addis Ababa. The general objective of the study is to assess the economic impacts of climate change on Maize productivity in Decha and make recommendations for strategies that could be adopted to mitigate the economic impact of climate change. The data were analyzed by using Statistical Package for Social Science (SPSS). Descriptive statistics such as frequency, mean, percentage, pie chart, bar graph, t-test and chi-square were used. The Results of the study indicate that climate change has an adverse impact on maize production in Decha woreda. According to the regression results, increase in temperature between March and May and increase in precipitation between June and August will have a negative impact. Increase in precipitation between March and May will have a positive impact on Maize productivity in Decha. Overall, the study found that temperatures have a larger effect on Maize productivity compared to precipitation. Predictions from nine out of the ten climate change scenarios used in the study indicate that Maize output will decrease by up to $23 \%$ by year 2019 . In line with the results, the study recommends that urgent measures be undertaken to mitigate the impact of climate change on Maize production. These measures include: research and development of agricultural technologies, investment in irrigation infrastructure and dissemination of information to farmers on climate change and possible impacts.
\end{abstract}

Keywords: Maize, Wheat, Climate, and soil

DOI: $10.7176 / \mathrm{JESD} / 10-13-01$

Publication date:July $31^{\text {st }} 2020$

\section{INTRODUCTION}

An Ethiopian economy is heavily reliant on agriculture. Agriculture is the major economic sector and the main source of livelihood for the majority of the people in Ethiopia. According to CSA (2015), 85 percent of the total population of the nation lives in rural areas and 90 percent of the population depends on the agricultural sector.

According to the Ministry of Agriculture (2015), the agricultural sector can be divided into six sub-sectors namely industrial crops, food crops, horticulture, fisheries and forestry. In terms of their contribution to agricultural output, food crops such as maize, wheat and bean among others contribute the highest while livestock and fisheries contribute the least. Industrial crops such as tea, coffee and sunflower among others make the highest contribution to agricultural exports followed by horticulture.

Among the food crops sub-sector, Maize is the most important since it is Decha principal staple food crop. It is the largest source of calorie intake, contributing about a third of calorie intake, for Decha woreda population. In terms of area under cultivation, about 1.4-1.6 million hectares are set aside for growing of Maize making it the biggest crop grown in terms of area under cultivation. Most Maize in Decha is grown by small scale farmers who produce about $75 \%$ of the total production. Maize plays an important role in the production patterns of small scale farmers, accounting for $28 \%$ of their gross output (Mathenge and Tschirley, 2014).

The falling maize yields witnessed from the early 1990's could be attributed to such factors as shrinking land sizes and high cost and increased adulteration of inputs. Other factors also include limited access to affordable credit, low and declining soil fertility, limited absorption of modern agricultural technology, pre and postharvest crop losses (Ministry of Agriculture, 2019).

In addition to the above factors, policymakers have begun to recognize the adverse role being played by climate change. Drought and unpredictable weather conditions have led to a succession of crop failures. Climate change is probably the most complex and challenging environmental problem facing the country today. The problem posed by climate change is further compounded by the increasing human population and demand for more agricultural land for food production. This has resulted in the destruction of the vegetation cover and subsequently rampant environmental degradation. Climate change is expected to cause poor crop productivity, outbreaks of diseases and vectors and rampant soil erosion.

The Ethiopian economy is highly reliant on agriculture. Agriculture contributes a significant share to the Country's GDP, total employment and export earnings and provides a source of livelihood for a large part of the population especially in the rural areas. Maize is a key sub- sector in the agricultural sector. Maize is the most widely grown in the country in terms of area under cultivation. It provides the Ethiopian population with a third of their calorie intake and a key source of farm incomes especially in the maize surplus areas. Food security in Ethiopia and maize production are closely interlinked. At the country level, the availability of maize determines 
whether the country is food secure or not (Nyoro et al., 2007). This is also true at the households level, more so in the rural areas.

However, despite the importance of maize to the country, production especially in the last decade has been poor. The reasons for this include the high cost and increased adulteration of inputs, low and declining soil fertility, decreasing land sizes, limited access to affordable capital and low absorption of modern technology (Ministry of Agriculture, 2019). Besides the above factors, policymakers have begun to recognize the increasingly adverse role being played by climate change on maize production. Changeable weather conditions have been blamed for a succession of maize crop failures forcing the Decha woreda to import maize to feed its population.

Most studies conducted on the impact of climate change on agricultural sector in Ethiopia have analyzed the impact of climate on general agriculture. It is important to analyze the impact of climate change at individual crop or animal level so as to be able to get a better understanding of how climate change will affect agriculture production in Decha woreda. This study sought to address this gap in knowledge by providing insights on how climate change affects maize productivity.

This study sought to provide important insights for policy makers in the agricultural sector on the effects of climate change on maize production and food security in Decha. Maize availability and food security in Decha are closely intertwined. With this close link between food security of the country and maize production, it is important for policy makers to get a clear understanding of the effects of climate change on maize production. The study also sought to propose adaptation options that could be taken up to mitigate the impact of climate change on maize production in Decha. Finally, the study contributes to the growing literature on climate change in Decha.

This paper is organized as follows: The first is Introduction, Statement of the problem, objective and scope of the study about the economic impact of climate change on Maize production in Decha woreda. Section two provides literature reviews, including theoretical and empirical evidence. Section three discusses Model specification, data source and description, estimation techniques. Section four presents analysis and results of the study. Finally, section five presents conclusion and policy implication based on the estimated results.

\section{LITERATURE REVIEW}

\section{Theoretical Literature}

The production function approach was the pioneering approach used to analyze the impact of climate change on agriculture. The approach is based upon experimental or empirical production functions where environmental variables such as precipitation or temperature are inputs. These environmental variables in the production function are varied so as to estimate the impacts of climate change on yields These changes in yields are then incorporated in economic models so as to predicate the changes in welfare as a result of climate change (Mendelsohn et al., 1994).

Production function approach has the advantage of providing estimates of impact of climate that are free of bias as a result of the determinants of agricultural production that are beyond a farmer's control such as soil quality (Deschenes and Greenstone, 2006). In addition, the approach provides better predictions of the impact of climate change on agricultural yields because of its use of controlled experiments (Mendelsohn et al., 1994; Deschenes and Greenstone, 2006).

\section{The Ricardian Approach}

According to Mendelsohn et al., (1994), the Ricardian approach estimates the impact of climate change by looking at how climate in different places affects farm revenue or the value of the farmland. They note that by looking at the effect of climate variables such as temperature or precipitation on farm revenues or value of the farmland, the approach is able to incorporate farmer's adaptations to climate change.

\section{Empirical Studies}

This section presents a survey of empirical studies conducted on the economic impact of climate change on agriculture. Rosenzweig et al., (1994) investigated the potential impact of global climate change on world food supply. The study used data drawn from other individual studies so as to obtain the world picture of the simulated change in crop yield associated with different climate change scenarios. To simulate the economic consequences associated with the different changes in yield associated with different climate scenarios, the study used a world food trade model. The study found out that developing countries were more vulnerable to climate change than the developed countries. The study also found out that adaptation options taken up at the farm level in developing countries didn't reduce this gap in vulnerability.

The findings by Rosenzweig et al., (1994) were supported by findings of another study by Parry et al., (1999). Parry et al., (1999) investigated the potential impact of climate change on world food security using crop growth models for wheat, rice, maize and soybeans and simulated the changes of crop yields as a result of climate change. They found out that climate change will affect agricultural production more in developing countries than in developed countries particularly those located in Africa. It further noted that, agricultural production in mid and high latitudes will benefit from climate change while agricultural production in low latitudes will suffer.

Chang (2002) used the production function approach to analyze the impact of climate change on agricultural 
sector. He used yield regression models and factored in farmer's adaptation responses. The study focused on crops including rice, corn, wheat, sorghum, soybeans, carrots, tea and sesame among others. Chang (2002) noted that temperature and precipitation have significant impact of crop yields. He also found that climate change will have an overall positive impact on maize production.

The study was conducted in six agricultural kebels namely Gebera, Dubiyo, Geca, Kutti, Erimo and Baha kebels. The study focused on a variety of crops such as maize, wheat, sorghum, and sugarcane, beans, bananas, millet and pigeo peas among others. The study used the FAO Penman-Monteith model to investigate the impact of climate change on crop water requirements and found out that climate change does affect crop water usage. The study showed that there is an increase in crop water use as a result of an increase in temperatures.

Kabubo-Mariara and Karanja (2007) investigated the economic impact of climate on Decha crop agriculture based on a cross sectional survey of 816 households. The authors used a Ricardian approach to analyze the impact of climate variables on net revenue per hectare. They found out that climate change affects agricultural productivity. The study found that high temperatures negatively affect crop production while high precipitation had a positive effect. Their results indicated that medium and low potential agro-ecological zones will be the most affected by climate change while high potential zones may actually gain from climate change. The study also found out that farmers were aware of the changing climate conditions and had started taking up measures to mitigate its effects.

The results of above study were supported by another study by Kabubo-Mariara (2008) which investigated the impact of climate change on crop selection and the adaptation measures taken up by farmers. The study used a probit model based on cross-sectional data to analyze the impact of climate change on crop selection and descriptive analysis to evaluate the adaptation measures being taken up by farmers. To analyze the impact of climate change on crop selection using the probit model, the crops were divided into major food crops, minor food crops and cash crops. The results of the study indicated the choice to grow a crop or a group of crops is affected by climate change. The results also showed that temperature has a bigger influence on the choice than precipitation. The study found out that for major food crops such as maize, the decision whether to grow or not was affected by both temperature and precipitation. Both temperature and precipitation also had a significant influence on decision to grow either tea or coffee, two major cash crops.

The earlier studies in Ethiopia used the production function approach in analyzing the impact of climate change on agriculture while later studies used the Ricardian approach. In addition, most studies in Ethiopia have analyzed the impact of climate change either at an aggregate crop level or livestock level. One study that attempted to analysis at an individual crop level was by Mati (2002). However, the study focused on only two agro-ecological zones though maize is grown in nearly all seven agro-ecological zones in the country. The study further failed to project how maize production will respond to future climate changes scenarios. The current study attempted to fill this gap by analyzing the impact of climate change on maize production in Decha.

\section{RESEARCH METHODOLOGY}

This chapter describes the framework that was used to analyze the impact of climate change on maize production in Decha woreda. Both primary and secondary data collected were used. Primary data were collected from sample households through structured questionnaire, interview and secondary data from concerned line offices such as agricultural office, education office, and from administration office of the woreda. Reviews of relevant books, journals, articles, and other published and unpublished document was also carried out.

The household data for this study is based on a sample of 1446 households. The household data was collected by Decha woreda Institute of Agricultural Policy and Development through interviews of farmers in the year 2019. The data coverage was 22 districts spanning over 6 provinces.

\section{Empirical Model}

This study uses the Ricardian Approach to investigate the impact of climate change on maize production in Decha woreda. The Ricardian model is a cross sectional model that is used to evaluated the long term impacts of climate change on agriculture. The Ricardian model estimates the impact of climate change by looking at how climate affects farm revenue or the value of farmland.

The Ricardian function following Mendelsohn et al. (1994) can be presented as;

$\mathbf{R}=\left(\sum \mathbf{P}_{\mathbf{m}} \mathbf{Q}_{\mathbf{m}}(\mathbf{X}, \mathbf{C}, \mathbf{Z}, \mathbf{S})-\sum \mathbf{P x X}\right)$

Where $\mathrm{R}$ is net farm revenue per hectare, Pm is the market price of maize, Qm is maize output,

$\mathrm{X}$ is a vector of purchased inputs other than land, $\mathrm{C}$ is a vector of climate variables, $\mathrm{Z}$ is a vector of soil variables, $\mathrm{S}$ is the vector of the socio-economic variables and $\mathrm{Px}$ is the vector of input prices. The farmer is assumed to choose $\mathrm{X}$ to maximize the net farm revenue $(\mathrm{R})$ given soil, climate and socio-economic variables.

Maximizing net revenue in equation (1) subject to inputs leads to a reduced form Ricardian model where net revenue $(\mathrm{R})$ is a function of exogenous variables. These exogenous variables are $\mathrm{C}$ (climate variables), $\mathrm{Z}$ (soil variables) and $\mathrm{S}$ ( the vector of the socio-economic variables). The reduced form Ricardian model takes up the general form: 
$\mathbf{R}=\mathbf{f}(\mathbf{C}, \mathbf{Z}, \mathbf{S})$

Equation 2 is said to follow a quadratic function with the climatic factors having squares in order to capture the nonlinear relationship between net revenue and climatic factors (Mendelsohn et al., 1994). Therefore the equation to be estimated becomes;

$\mathrm{R}=\beta \mathrm{o}+\beta 1 \mathrm{C}+\beta 2 \mathrm{C} 2+\beta 3 \mathrm{Z}+\beta 4 \mathrm{~S}+\mu$

Definition and Measurement of Variables

The definition and measurement of independent variables used in the analysis are presented in below. The dependent variable is this study is net maize revenue per hectare computed by removing variable costs from the gross maize revenue. The variable costs represent the cost of the purchased inputs such as fertilizer and seeds, the cost of labor and the cost of land preparation.

In the below table, column one represents the variable name, column two the definition and measurement of each variable and third column, the hypothesized relationship between the dependent variable and each independent variable.

\begin{tabular}{|llc|}
\hline VARIABLE & MEASUREMENT & EXP CTED SIGN \\
\hline $\begin{array}{l}\text { Precipitation } \\
\text { Temperature }\end{array}$ & $\begin{array}{l}\text { Climate normal monthly mean }+ \\
\text { Climate normal monthly mean - Climate normal monthly mean - }\end{array}$ & + \\
Farm size & $\begin{array}{l}\text { Climate normal monthly mean - } \\
\text { Size of the farm in acres }+\end{array}$ & + \\
Household size & $\begin{array}{l}\text { The number of people in the household }+ \\
\text { Average years of } \\
\text { education }\end{array}$ & $\begin{array}{l}\text { The average years of education of total }+ \\
\text { household members }\end{array}$ \\
$\begin{array}{l}\text { Distance to the } \\
\text { extension services } \\
\text { Soil variable }\end{array}$ & The distance to the nearest extension service provider & + \\
\hline
\end{tabular}

\section{RESULT AND DISCUSSION}

The descriptive results indicates that $88 \%$ of the households were male headed. The results also indicated that the average size of the households is about 6.67 persons per household.

The results also show that the average farm size per household is 5.082 hectare with largest recorded farm size being 204 acres and the least being 0.095 acres. The results also indicate that the average distance to extension services provider is about 5.39 kilometers with the largest distance reported being 62 kilometers with the least being zero kilometers. Only $9 \%$ of the households are found in districts where soil variables are the dominant type.

The results indicate that the average temperature between March and May is $18.100 \mathrm{C}$ while between June and August is $17.670 \mathrm{C}$. The average temperature between September and November is $18.530 \mathrm{C}$. The district with the highest temperature is Geca district with $25.810 \mathrm{C}$ while Dubiyo district has the lowest temperature of about $15.720 \mathrm{C}$.

The average precipitation for the months between September and November is $78.74 \mathrm{~mm}$. The districts that receive the highest rainfall of March to May are $123.686 \mathrm{~mm}$ while for the months of June to August is 72.354 $\mathrm{mm}$. The average precipitations are Kutti, Erimo and Gebera kebels.

The 2019 household data set consisted of 1446 households of which 1357 grew maize. Normality tests are then undertaken to inspect if the variables were normally distributed. The rule of the thumb about normal distribution of data is that the variables should have a kurtosis of below three and a skewness of zero.

A $\log$ transformation was done to variables with the exception of gender of the household and soil type that weren't normally distributed to make them satisfy the normality assumption. However, this did not improve much the normality of these variables.

However, the most important basis for testing the normality assumption is through checking the distribution of the residuals. For OLS estimation to be used, the residuals must be normally distributed (Gujarati, 1995). Results in appendix I indicate that the residuals are normally distributed which implies that OLS may be used.

\section{Estimation Issues}

The study considers the following estimation issues that may affect the regressions results.

A. Heteroscedasticity

This is dealt with by estimating White heteroscedasticity consistent variances and standard errors. It is the most recommended way of dealing with heteroscedasticity (Gujarati, 1995).

B. Multicollinearity

Due to the quadratic nature of the climate variables a certain degree of, Multicollinearity is expected. It is expected that the squared climate values are highly correlated to the non-squared values which introduces an element of Multicollinearity. Another element of Multicollinearity may exist between climatic values of different seasons. However, this study ensures that the extent of this problem is reduced as far as possible by dropping some of the troublesome variables and demeaning the climatic data (subtracting the mean from the data). According to 
Amiraslany (2010), demeaning reduces Multicollinearity among independent variables. The troublesome variables the study drops include the average temperature and precipitation between the months of September and November and the average temperature between the months of June and August.

The results indicate that there exists a significant non-linear relationship between climate variables and net farm revenue per hectare as shown in the three models. According to the results, high temperatures between March and May have an adverse effect on net farm revenue. This may be due to the disruptive role high temperatures during that period may have on the formative growth of the maize crop (formative growth of the maize plant takes place between March and May). The results also indicate that the average temperature between March and May has an inverted $U$ shaped relationship with net maize revenue per hectare. The positive squared term for MarchMay average temperature indicates that there is a minimum level of temperature during that period required for maize production and that more or less temperature during that period will increase net farm revenue per hectare.

\section{Summary and Conclusions}

This study analyzed the impact of climate change on maize production in Decha using a Ricardian model. The data for this study was based on a sample of 1357 households. The temperature data that was used in the study was from Satellite climate data while precipitation data was from ARTES (African Rainfall and Evaluation System). Soil data was sourced from the Decha soil survey conducted by the Decha Agricultural Office.

The general objective of the study was to conduct an assessment of the potential impact of climate change on maize production in Decha. Another objective was to simulate future impacts of climate change on maize production in Decha and make recommendations for strategies that could be adopted to mitigate the impact of climate change on maize production.

The regressions results suggest that climate has a significant impact on maize production. Increase in MarchMay temperature and June -August precipitation was found to have an adverse impact on maize production while increase in March-May precipitation was found to have a positive impact. The study found out that temperature has a bigger impact on maize production as compared to precipitation. These results are in line with expectation that climate change will negatively affect agricultural production in Africa.

The results indicate that overall climate change will have an adverse effect on maize production in Decha and hence may also have an adverse effect on food security. This is noted because of the close relationship between maize availability and food security as maize is the country principal food crop. Therefore, policy efforts should be directed at addressing the impact of climate change on maize production.

One critical policy intervention would be raising awareness among maize farmers on climate change by providing climate change related information. It is estimated that only about $50 \%$ of farmers in Africa are aware of climate change and its impact on agriculture. Increasing awareness would require that the government actively monitors climate change, encourages research into climate change and sets up information dissemination channels to farmers.

Decha is fresh water scarce country and climate change is expected to further reduce the availability of fresh water in the country. Given this, there is a need for proper management of the few fresh water resources available. The government should construct water pans and dams, protect water towers and encourage rainfall harvesting. In addition, the government should construct water recycling facilities and raising awareness on the need to use water sustainable.

Irrigation is another policy option that could be considered to mitigate the impact of climate change. Maize production is largely dependent on rainfall and a paradigm shift from rain fed to irrigation based maize production may not only increase production but make it resilient to climate change. Finally, effective dissemination of climate related information to maize farmers should be urgently undertaken. Farmers should be informed on climate change and its likely impacts on maize production.

\section{REFERENCES}

Chang, Ching!Cheng (2002). "The potential impact of climate change on Taiwan's agriculture." Agricultural Economics 27, no. 1: 51-64.

Deressa,Temesgen Tadesse (2007). "Measuring the economic impact of climate change on Ethiopian agriculture: Ricardian approach." World Bank Policy Research Working Paper 4342, World Bank, USA.

Deressa, Temesgen Tadesse, Rashid Hassan, and Daneswar Poonyth (2005). "Measuring the impact of climate change on South African agriculture: the case of sugarcane growing regions." Agrekon 44, no. 4: 524-542.

Deschenes, Olivier, and Michael Greenstone (2007). "The economic impacts of climate change: evidence from agricultural output and random fluctuations in weather." The American Economic Review, no.97 (1): 354-385.

Downing, C., F. Preston, D. Parusheva, L. Horrocks, O. Edberg, F. Samazzi, R. Washington, M. Muteti, P. Watkiss, and W. Nyangena (2008). "Kenya: climate screening and information exchange." Report no. AEA/ED05603 2, DFID,UK.

Downing, Thomas E (1992). "Climate change and vulnerable places: Global food security and country studies in 
Zimbabwe, Kenya, Senegal and Chile." Research Report-Environmental Change Unit, University of Oxford, UK.

Fezzi, Carlo, Ian Bateman, and Wolfram Schlenker (2010). "The Ricardian Approach with Panel Data and Flexible Functional Forms: An Additive Mixed Model applied to England and Wales farmland values." contributed paper presented at the Fourth World Congress of Environmental and Resource Economists, Montreal Canada.

Gbetibouo, Glwadys Aymone, and Rashid Hassan (2005). "Measuring the economic impact of climate change on major South African field crops: a Ricardian approach." Global and Planetary Change 47, no. 2: 143-152.

Guantai, S. M., and P. Seward (2010). "Maize Handbook." ACDI/VOCA, Kenya Maize Development Programme, Nairobi.

Karanja, Daniel David (1996). "An economic and institutional analysis of maize research in Kenya." MSU International Development International Development Working Paper 57, Michigan State University, USA.

Karanja, Fredrick K (2006). "CROPWAT model analysis of crop water use in six districts in Kenya." CEEPA $D P 35$, University of Pretoria, South Africa. Kenya National Bureau of Statistics (1975-2012). Kenya Economic Survey. Government Printer, Nairobi.

Kirimi, Lilian, Nicholas Sitko, Thomas S. Jayne, Francis Karin, Milu Muyanga, Megan Sheahan, James Flock, and Gilbert Bor (2011). "A Farm Gate-to-Consumer Value Chain Analysis of Kenya's Maize Marketing System." Tegemeo Institute of Agricultural Policy and Development Working Paper 44, Egerton University, Kenya.

Kurukulasuriya, Pradeep, and Shane Rosenthal (2003). "Climate change and agriculture." World Bank Environment Department Paper 91, World Bank, USA.

Kurukulasuriya, Pradeep, Robert Mendelsohn, Rashid Hassan, James Benhin, Temesgen Deressa, Mbaye Diop, Helmy Mohamed Eid et al.,(2006) "Will African agriculture survive climate change?." The World Bank Economic Review 20, no. 3: 367-388.

Ministry of Environment and Mineral Resources (2009). National climate change response strategy. Government Printer. Ethiopia.

World Bank. Kenya Agricultural Policy Review: Current Trends and Future Options for Pro-Poor Agricultural Growth. Report no. 53707-ke, World Bank, USA. 